\title{
ANOMALOUS ORIGIN OF CORONARY ARTERIES: ANATOMICAL STUDY AND CLINICAL CORRELATES
}

\author{
K. Jayasree ${ }^{1}$, Ashalatha P. R2 \\ 1 Professor, Department of Anatomy, Govt. Medical College, Manjeri, Kerala. \\ ${ }^{2}$ Associate Professor, Department of Anatomy, Govt. Medical College, Manjeri, Kerala.
}

\begin{abstract}
AIMS AND OBJECTIVES

The arterial supply of the heart is obtained by the two coronary arteries, right and left, which originate respectively from the right and left aortic sinuses of ascending aorta. Considering all congenital cardiac anomalies, the anomalous origin of coronary arteries is relatively rare, but clinically much significant when present. Anomalous coronary arteries and their clinical relevance have been reported by various workers as cases identified in cardiac patients, in cadaveric hearts and in autopsy findings. The present study aims to identify the prevalence of anomalous origin of coronary arteries and correlate them with possible clinical manifestations.
\end{abstract}

\section{STUDY SETTINGS AND DESIGN}

A cadaveric study was conducted in human hearts in the Department of Anatomy, Govt. Medical College, Kozhikode, Kerala.

\section{MATERIALS AND METHODS}

The study was done in 60 hearts, 30 from adult cadavers and 30 from stillborn full-term foetuses. In each heart the origin of both coronary arteries were carefully studied, looking particularly for anomalies if any. The observations were recorded and photographed.

\section{RESULTS AND ANALYSIS}

In the present study in two hearts, both foetal coronary arteries had anomalous origin. In both the origin of right coronary artery was anomalous, one originating from left aortic sinus and the other from pulmonary trunk. In the former case, the left coronary artery had origin from pulmonary trunk. The incidence of anomalous origin of right coronary artery was $3.3 \%$ and that of left coronary artery was $1.7 \%$.

\section{CONCLUSION}

Though many patients with similar anomalies of coronary arteries may remain asymptomatic, reports from clinical studies indicate that some of them present with serious complications like attacks of syncope, pulmonary coronary steal, myocardial ischaemia and sudden cardiac death. Such cases pose diagnostic challenge to paediatricians, physicians, cardiologists and cardiothoracic surgeons. The awareness of the possibility of anomalous coronary arteries is essential for its proper recognition and diagnosis in early stages of life, which will enable timely surgical intervention and better prognosis. In this background, we discuss the clinical significance of anomalous origin of coronary arteries with review of relevant literature.

\section{KEYWORDS}

Coronary Arteries, Aortic Sinuses, Anomalous Origin, Pulmonary Trunk.

HOW TO CITE THIS ARTICLE: Jayasree K, Ashalatha PR. Anomalous origin of coronary arteries: anatomical study and clinical correlates. J. Evolution Med. Dent. Sci. 2016;5(64):4588-4592, DOI: 10.14260/jemds/2016/1045

\section{INTRODUCTION}

Heart is the first organ to start functioning in the human body, which continues to beat throughout life. This necessitates a high oxygen demand for the myocardium, which is provided by the arteries that nourish the heart, the right and left coronary arteries. The coronary arteries are the biggest vasa vasora, as the heart is a modified blood vessel developmentally. The coronary arteries arise from two of the three aortic sinuses or sinuses of Valsalva present at the root of ascending aorta. The right artery arises from the anterior ('right coronary') aortic sinus: the ostium is below the margin of the cusps in $10 \%$.

Financial or Other, Competing Interest: None.

Submission 04-07-2016, Peer Review 29-07-2016,

Acceptance 03-08-2016, Published 11-08-2016.

Corresponding Author:

Dr. K. Jayasree,

Professor, Department of Anatomy,

Govt. Medical College,

Manjeri, Kerala.

E-mail: jsreek@gmail.com

DOI: $10.14260 /$ jemds $/ 2016 / 1045$
The left artery arises from the left posterior ('left coronary') aortic sinus; the ostium is below the margin of the cusps in $15 \%{ }^{1}$

Reports of anomalous origin of coronary arteries, such as the origin of right coronary artery from left aortic sinus, the left from right aortic sinus, both arteries from the same aortic sinus, both or either artery from pulmonary trunk, etc. are available in literature. Roberts W.C. (1986) ${ }^{2}$ has reviewed the major anomalies of coronary arterial origin seen in adulthood.

The first cases of anomalous origin of the right coronary artery from the pulmonary artery were described by Brooks in $1885,{ }^{3}$ and since then only 100 cases have been reported. It is a rare congenital anomaly with an estimated prevalence of $0.002 \%{ }^{4}$ Most patients are asymptomatic and their anomalies are detected incidentally. This is in contrast with the anomalous origin of the left coronary artery from the pulmonary artery, which is characteristically fatal during early infancy without immediate surgical management. Anomalous origin of left coronary artery from pulmonary artery is a rare congenital cardiovascular malformation, 
which occurs in approximately 1 in 300,000 live births or $0.25 \%$ to $0.5 \%$ of children with congenital heart disease. ${ }^{5}$ The incidence of abnormal aortic origin of coronary arteries is low with reported values of $0.64 \%$ of births. ${ }^{6}$ and $0.17 \%$ in asymptomatic children and adolescents. ${ }^{7}$

\section{MATERIALS AND METHODS}

The study of the gross anatomy of human coronary arteries with special reference to their origin was conducted in the Department of Anatomy, Govt. Medical College, Kozhikode; 30 adult cadavers (26 male and 4 female) which were mainly meant for the dissection of the undergraduate students and 30 stillborn full-term foetuses ( 22 male and 8 female) which were collected from the Institute of Maternal and Child Health attached to the Govt. Medical College, Kozhikode, were utilized for the study. The fetuses were preserved using $10 \%$ formalin by multiple injections and kept immersed in formalin till they were taken out for dissection.

For the study in the cadavers thorax was opened, pericardium was incised to expose the heart, keeping the heart in situ. In each heart, the right and left coronary arteries were carefully dissected. The origin of both coronary arteries from the aortic sinuses were noted, looking particularly for anomalies of origin if any.

In the foetuses, the heart was opened by the following incisions in the thorax - a vertical midline incision extending from the root of the neck to the lower end of the sternum and two horizontal incisions to the left, one starting from the upper end and the other from the lower end of the first incision. The pericardial cavity was opened and the heart was removed by cutting superior and inferior venae cavae, the pulmonary veins, the arch of aorta and pulmonary trunk.

The coronary system of each foetal heart was carefully dissected and studied by the same method as in the cadaver.

In each heart, the observations regarding the origin of the coronary arteries were recorded. Those hearts which showed anomalies in origin were meticulously studied and photographed.

\section{RESULTS AND ANALYSIS}

Out of the 60 hearts studied, the origin of both right and left coronary arteries were normal in 58 hearts. Two male hearts, both foetal showed anomalous origin of the coronary arteries. In the first one, the right coronary artery was originating from the pulmonary trunk from its anterior aspect, turned to the right, reached the atrioventricular sulcus and coursed normally. The right aortic sinus showed no coronary ostium. The origin of the left coronary artery was normal from the left aortic sinus in this case (Fig. 1).

In the second case, the right coronary artery was originating from the left aortic sinus from its mid portion and emerged on the sternocostal surface by passing between ascending aorta and pulmonary trunk, reached the atrioventricular sulcus and had a normal course thereafter. There was no coronary ostium in the right aortic sinus. In the same heart, the left coronary artery was originating from the pulmonary trunk at its posterior wall, emerged between the pulmonary trunk and the left auricle and continued as the anterior interventricular branch, there being no circumflex branch (Fig. 2). The origin of both right and left coronary arteries were normal in all the 30 adult hearts studied.
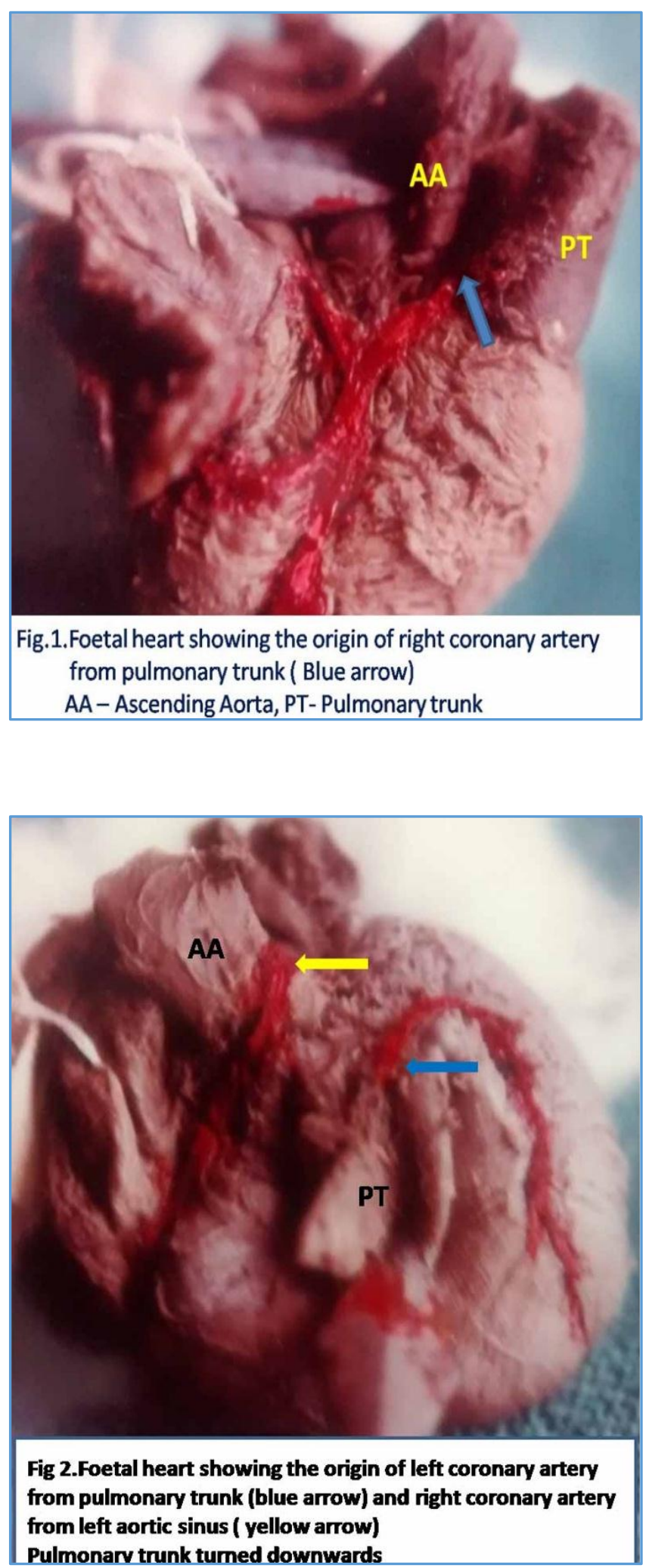

\section{DISCUSSION}

During the developmental stage, connection of the coronary arteries to the aorta occurs by ingrowth of arterial endothelial cells from the arteries into the aorta, a mechanism by which the coronary arteries "invade" the aorta. ${ }^{8}$ Normally, right coronary artery arises from right 
aortic sinus and the left from left aortic sinus. As an anomaly, the coronary arteries may occasionally arise by a common trunk from the ascending aorta or from the opposite aortic sinus or very rarely from the pulmonary trunk.

In the present study, out of the 60 specimens, 58 hearts showed normal origin of right coronary artery. In the remaining 2 hearts, both were from male foetuses. The right coronary artery had anomalous origin (3.3\%). In one of them, the right coronary artery was originating from the pulmonary trunk (Frequency 1.7\%) and in the other from the left aortic sinus (Frequency 1.7\%). These anomalies become important when the origin and course of the arteries are in such a way that the anomaly causes or predisposes a patient to the development of serious manifestations like myocardial ischaemia or sudden cardiac death, especially in those cases where the anomalous artery passes between the great arteries. In the present study, the right coronary artery having anomalous origin from the left aortic sinus had such a course.

Anomalous origin of right coronary artery is a rare congenital anomaly that was first described in 1948 by White and Edwards. ${ }^{9}$ The prevalence of this anomaly in the white population, as determined from autopsy studies is $0.026 \% .10$ Among congenital coronary artery anomalies, the anomalous coronary origin from the pulmonary artery is an extremely rare form. Four variations of this condition have been described: Anomalous origin of the Left Coronary Artery from the Pulmonary Artery (ALCAPA), Anomalous origin of the Right Coronary Artery from the Pulmonary Artery (ARCAPA), origin of an accessory coronary artery from the pulmonary artery and the origin of the entire coronary circulation from the pulmonary artery. ${ }^{11}$

Williams et $\mathrm{al}^{4}$ in 1990, published a review of seven previously reported cases of ARCAPA. Though ARCAPA is well tolerated in the neonatal period, once the pulmonary resistance falls the fully oxygenated blood arriving in the anomalous coronary via collateral vessels from the normally arising coronary is stolen by the pulmonary trunk resulting in chronic myocardial ischaemia. ${ }^{12}$

In the study done by Maroules and Associates. ${ }^{13}$ using multidetector computerized tomography, for the evaluation of a systolic murmur in a 35-year-old asymptomatic man, a grossly dilated right coronary artery was found originating from the main pulmonary artery. Direct coronary angiography confirmed the anomalous origin.

Anomalous origin of coronary arteries from the contralateral sinuses of Valsalva is rarely diagnosed in children and adolescents. ${ }^{10}$ The right coronary artery originating from the left aortic sinus is a rare variation and in angiographic studies the incidence has been reported as 0.17 $0.38 \% .6,14$ and considered as relatively benign in the absence of arteriosclerosis. Palimar and Associates ${ }^{15}$ reported a rare case of anomalous origin of right coronary artery from the left aortic sinus, observed during the autopsy of 34-year-old woman. The right and left coronary ostia were laid at the same level in the left aortic sinus at a distance of $2 \mathrm{~mm}$. The origin of the right coronary artery from left sinus of Valsalva is a risk factor for sudden death during exercise. An anomalous origin of right coronary artery from the left sinus of Valsalva associated with syncope in an young athlete after a football game has been reported by Lilly et al, 16 in which case the right coronary artery began adjacent to the ostium of left main coronary artery, coursed between aorta and pulmonary trunk and had a characteristic "slit-like" ostial orifice. The presence of ischaemic symptoms may be useful in defining a high-risk population. Such symptoms are uncommon, particularly in young patients who may present with a single episode of syncope or sudden cardiac death.

Ho JS17 reported a case of a 41-year-old patient with no relevant cardiac history, in whom evaluation of episodic syncope revealed an anomalous origin of right coronary artery from the left aortic sinus. It is well established that an anomalous origin of the right coronary artery can lead to angina pectoris, myocardial infarction or sudden death in the absence of atherosclerosis. ${ }^{18}$ Though the pathophysiologic basis for this association is unclear, the mechanical compression of the right coronary artery by the great vessels is the usual explanation, as the anomalous right coronary artery generally courses between the aorta and the pulmonary artery to its normal position.

Anomalous origin of left coronary artery from the pulmonary artery is a serious congenital cardiac malformation. In the present study, out of the 60 hearts only one foetal heart had the origin of the left coronary artery from the pulmonary trunk (Frequency 1.7\%). This anomaly was observed in the same foetal heart in which the right coronary artery had anomalous origin from the left aortic sinus. After the anomalous origin, the left coronary artery continued its course as the anterior interventricular artery without giving a circumflex branch.

Anomalous origin of the left coronary artery from the pulmonary artery was first reported by Bland, White and Garland in 1933 and this malformation was named BlandWhite-Garland syndrome. ${ }^{19}$ An embryological defect during foetal cardiac development results in the left coronary artery arising from the pulmonary artery instead of the aorta. 20 This defect may result from either abnormal septation of the conotruncus into the aorta and pulmonary artery or from persistence of the aortic buds that eventually form the coronary arteries. This anomaly is usually isolated, but has occasionally been associated with other congenital heart defects such as patent ductus arteriosus, ventricular septal defect, Tetralogy of Fallot or coarctation of aorta. ${ }^{21}$

Perry and $\operatorname{Scott} 22$ have reported anomalous origin of the left coronary artery from the pulmonary artery in 11 patients at the Children's Hospital of the District of Columbia from 1946 to 1969. Anomalous origin of the left coronary artery from the pulmonary artery is a serious congenital cardiac defect associated with high mortality rate in infancy.

In the case series reported by Dilawar and Ahmad 23 involving 5 patients with age range of 2-12 months, admitted with symptoms of tachypnoea and poor feeding with irritability, anomalous origin of left coronary artery from pulmonary artery was confirmed in 4 patients by echocardiography and coronary angiography.

Lardhi24 in a review article described the anomalous origin of left coronary artery from pulmonary artery as a rare but potentially lethal congenital heart disease and a rare cause of myocardial infarction and/or congestive heart failure in children. Infants with this anomaly appear normal at birth and usually do well for a short period before they become symptomatic, usually at 2-3 months when pulmonary arterial resistance drops to adult level. Family physicians and paediatricians should keep a high index of suspicion for this 
anomaly during workup of any infant or child presenting with symptoms of unexplained congestive cardiac failure, angina like symptoms, mitral insufficiency murmur or cardiomegaly. The mortality of untreated cases of anomalous origin of left coronary artery from pulmonary artery has been estimated to be more than $90 \%$ during the first year of life. ${ }^{25}$

Among coronary artery anomalies 'Anomalous Coronary Artery from the Opposite Sinus' poses a relatively higher risk of sudden death, particularly in the young and when the anomalous artery courses between the ascending aorta and pulmonary trunk. ${ }^{26,27}$

Cases of anomalous origin like the left coronary artery arising from the right aortic sinus or either of the arteries from the 'non-coronary' sinus were not found in the present study.

\section{CONCLUSION}

The anomalous origin of coronary arteries, either from the opposite aortic sinus or from the pulmonary trunk can lead to fatal outcome in many instances. In the present study the anomalous coronary arteries were observed in foetal hearts, indicating the possibility that such anomalies might have led to the failure to thrive at the beginning of life itself. Early detection of such anomalies of coronary arteries in childhood or adolescence and proper diagnosis by imaging techniques and timely surgical intervention will enable clinicians to save many patients from complications like massive myocardial infarction and sudden cardiac death.

\section{REFERENCES}

1. Standring S. Heart and mediastinum. Gray's Anatomy. The anatomical basis of clinical practice. $40^{\text {th }}$ edn Philadelphia: Elsevier Churchill Livingstone 2008:978-80.

2. Roberts WC. Major anomalies of coronary arterial origin seen in adulthood. Am Heart J 1986;111(5):941-63.

3. Brooks HSJ. Two cases of an abnormal coronary artery of the heart arising from the pulmonary artery: with some remarks upon the effect of this anomaly in producing cirsoid dilatation of the vessels. J Anat Physiol 1885;20 (pt 1):26-9.

4. Williams IA, Gersony WM, Hellenbrand WE. Anomalous right coronary artery arising from the pulmonary artery: a report of 7 cases and a review of the literature. Am Heart J 2006;152(5):1004. e9-17.

5. Keith JD. The anomalous origin of the left coronary artery from the pulmonary artery. Br Heart J 1959;21(2):149-61.

6. Kimbiris D, Iskandrian AS, Segal BL, et al. Anomalous aortic origin of coronary arteries. Circulation 1978;58:606-15.

7. Davis JA, Cecchin F, Jones TK, et al. Major coronary artery anomalies in a pediatric population: incidence and clinical importance. J Am Coll Cardiol 2001;37(2):593-7.

8. Sadler TW. Cardiovascular system. Langman's medical embryology. $12^{\text {th }}$ edn. Philadelphia: Lippincott Williams \& Wilkins 2012:188.

9. White NK, Edwards JE. Anomalies of the coronary arteries. Report of four cases. Arch Pathol (Chic) 1948;45(6):766-71.
10. Alexander RW, Griffiths GC. Anomalies of the coronary arteries and their clinical significance. Circulation 1956;14(5):800-5.

11. Yamanaka O, Hobbs RE. Coronary artery anomalies in 126,595 patients undergoing coronary arteriography. Cathet Cardiovasc Diagn 1990;21(1):28-40.

12. Mintz GS, Iskandrian AS, Bemis CE, et al. Myocardial ischemia in anomalous origin of the right coronary artery from the pulmonary trunk. Proof of a coronary steal. Am J Cardiol 1983;51(3):610-2.

13. Maroules CD, Adams DZ, Whiting ED, et al. Anomalous origin of the right coronary artery from the pulmonary artery. Evaluation with use of 64-slice multidetector computed tomography. Tex Heart Inst J 2013;40(1):1068.

14. Chaitman BR, Lesperance J, Saltiel J, et al. Clinical, angiographic and haemodynamic findings in patients with anomalous origin of the coronary arteries. Circulation 1976;53(1):122-31.

15. Palimar V, Pamidi N, Rakesh V, et al. Origin of right coronary artery from the left sinus of Valsalva. International Journal of Anatomical Variations 2008;1: 12-3.

16. Lilly SM, Schussler JM, Stoler RC. Anomalous origin of the right coronary artery from the left sinus of Valsalva associated with syncope in a young athlete. Proc Bay 1 Univ Med Cent 2011;24(1):13-4.

17. Ho JS, Strickman NE. Anomalous origin of the right coronary artery from the left coronary sinus: case report and literature review. Tex Heart Inst J 2002;29(1):37-9.

18. Taylor AJ, Rogan KM, Virmani R. Sudden cardiac death associated with isolated congenital coronary artery anomalies. J Am Coll Cardiol 1992;20(3):640-7.

19. Bland EF, White PD, Garland J. Congenital anomaly of coronary arteries: report of unusual case associated with cardiac hypertrophy. Am Heart J 1933;8:787-801.

20. Brotherton H, Philip RK. Anomalous left coronary artery from pulmonary artery (ALCAPA) in infants: a 5-year review in a defined birth cohort. Eur J Pediatr 2008;167(1):43-6.

21. Ogden JA. Congenital anomalies of the coronary arteries. Am J Cardiol 1970;25(4):474-9.

22. Perry LW, Scott LP. Anomalous left coronary artery from pulmonary artery, report of 11 cases: review of indications for and results of surgery. Circulation 1970;41:1043-52.

23. Dilawar M, Ahmad Z. Anomalous left coronary artery from pulmonary artery: case series and brief review. 0 J Ped 2012;2:77-81.

24. Lardhi AA. Anomalous origin of left coronary artery from pulmonary artery: a rare cause of myocardial infarction in children. J Family Community Med 2010;17(3):113-6.

25. Wesselhoeft H, Fawcett JS, Johonson AL. Anomalous origin of the left coronary artery from the pulmonary trunk: its clinical spectrum, pathology and pathophysiology, based on a review of 140 cases with seven further cases. Circulation 1968;38(2):403-25. 
26. Angelini P. Coronary artery anomalies: an entity in search of an identity. Circulation 2007;115(10):1296-305.
27. Kragel AH, Roberts WC. Anomalous origin of either the right or left main coronary artery from the aorta with subsequent coursing between aorta and pulmonary trunk: analysis of 32 necropsies cases. Am J Cardiol 1988;62(10 pt 1):771-7. 